\title{
Perancangan E-commerce Untuk Memperluas Produk Komunikasi di PT. Golden Communication Berbasis Web Mobile
}

\author{
Okta Veza*1 \\ ${ }^{1,1}$ Sekolah Tinggi Teknik Ibnu Sina Batam \\ Jln. Teuku Umar, Lubuk Baja, Batam, Kepulauan Riau, Indonesia \\ ${ }^{1}$ Program Studi Teknik Informatika, STT Ibnu Sina, Batam \\ e-mail: *10kta@stt-ibnusina.ac.id
}

\begin{abstract}
Abstrak
Bisnis E-commerce sudah menjadi trend dalam dunia bisnis saat ini. Website Ecommerce membantu bisnis penjualan kita dengan menawarkan produk dan servis secara online kepada konsumen diseluruh dunia. Website benar-benar menjadi solusi pemecahan untuk batasan lokasi bisnis dan menawarkan kecepatan penawaran dan bahkan memungkinkan menjadi penjual terbaik. E-commerce benar-benar membuat konsumen dapat menghemat waktu, dan membandingkan harga lebih mudah, selain itu menawarkan berbagai hal untuk dijual serta mengurangi berdesakan yang parah di toko. Fasilitas ini juga dikombinasikan dengan pembayaran yang cepat, pelacak order dan kecepatan pengiriman akan memenangkan hati konsumen.
\end{abstract}

Kata kunci-E-commerce, bisnis, website

\begin{abstract}
E-commerce business is ruling the world in the current trend. E-commerce website allows your business to sell you're offered products and services to your online customers all over the world. These websites break the barrier of geographical location of business and offers you a vast spectrum of audience and hence possibility of better overall sales. An E-commerce site saves buyers' time, makes prize comparisons simple, offers a variety of things to purchase and also reduces the annoyance of fighting through crowded stores. This facility which is combined with a quick payment, checkout, order tracking and quick shipping process wins the heart of consumers.
\end{abstract}

Keywords-E-commerce, business, website

\section{PENDAHULUAN}

E-Commerce adalah singkatan dari Electronic Commerce, yang sudah ada dalam Undang-undang (UU) Nomor 7 Tahun 2014 tentang Perdagangan telah mengatur kegiatan ecommerce dalam pasal 65 dan pasal 66. Sesuai pasal 66 UU tersebut, ketentuan lebih lanjut mengenai transaksi e-commerce diatur dengan atau berdasarkan Peraturan Pemerintah. $e$ commerce yang secara singkat dapat didefinisikan sebagai mekanisme transaksi jual dan beli dengan menggunakan fasilitas internet sebagai media komunikasi. Dalam pengertian yang lain, $e$ - commerce dapat diartikan sebagai rangkaian kegiatan usaha perdagangan yang sebagian atau seluruhnya menggunakan media internet sebagai media komunikasinya.

Keunggulan e-commerce adalah kemampuan bertransaksi kapanpun, diakses dari 
manapun, adanya jalur distribusi, dapat langsung melakukan pembelian, dan adanya penghematan biaya. Pembayaran terhadap transaksi perdagangan model e-commerce dapat dilakukan melalui banyak cara baik secara konvensional (kartu kredit, transfer antar rekening bank), maupun secara online (bitcoin, e-money, online banking, e-gold).

PT. Golden Communication merupakan sebuah perusahaan yang bergerak dibidang distributor dan penjualan kartu perdana telkomsel diantaranya kartu perdana paket internet, kartu perdana nomor cantik, kartu perdana reguler.

Seiring dengan perkembangan perusahaan proses transaksi dan promosi yang selama ini dijalankan kurang efektif dilakukan oleh perusahaan, Manajemen penjualan produk yang masih dilakukan secara manual. perusahaan hanya menggunakan marketing dan media cetak dalam penyampaian informasi promosi kepada konsumen dan outlet. Tidak adanya promosi dalam periklanan televisi, website, atau radio. Mekanisme seperti ini sangat memungkinkan akan timbulnya permasalah di perusahaan, diantaranya konsumen yang lokasinya jauh atau dekat dengan kota akan merasa kesulitan untuk berbelanja di PT. Golden Communication karena kurangnya informasi promosi. Solusi yang diajukan untuk mengatasi masalah PT. Golden Communication untuk mengembangkan bisnis penjualannya yaitu e-commerce. E-Commerce merupakan suatu kontak transaksi perdagangan antara penjual dan pembeli dengan menggunakan media internet. Keuntungan yang diperoleh dengan menggunakan transaksi melalui e-commerce adalah untuk meningkatkan pendapatan dengan menggunakan penjualan online yang biayanya lebih murah dan juga sekaligus biaya-biaya operasional seperti kertas, pencetakan katalog.

\section{METODE PENELITIAN}

\subsection{Indentifikasi Masalah}

Berdasarkan latar belakang masalah di atas, penulis mengindentifikasi masalah yang selama ini terjadi di PT. Golden Communication yaitu:

1. Manajemen penjualan produk penyampaian informasi promosi yang masih dilakukan melalui marketing dan media cetak di PT. Golden Communication belum berjalan secara optimal.

2. Belum tersedianya media promosi elektronik untuk memasarkan produk.

\subsection{Rumusan masalah}

Rumusan masalah yang penulis ajukan dalam skripsi ini berdasarkan latar belakang dan indentifikasi permasalahan di atas adalah:

1. Bagaimana cara merancang aplikasi e- commerce pada PT. Golden Communication?

2. Bagaimana cara mengimplementasikan aplikasi e-commerce pada PT. Golden Communication.

\subsection{Batasan Masalah}

Agar dalam penelitian dapat berjalan dengan baik dan terarah maka harus ada batasan terhadap ruang lingkup penelitian. Adapun pembatasan masalah pada penelitian ini adalah:

1. Jenis e-commerce yang dibuat adalah sistem komunikasi bisnis antar pelaku bisnis dengan konsumen (business to consumers).

2. Proses promosi e-comemerce yang dirancang hanya di wilayah kota batam.

3. Produk yang dijual berupa kartu perdana reguler, kartu perdana nomor cantik dan kartu perdana paket internet dari telkomsel.

\subsection{Tujuan Penelitian}

Adapun tujuan yang bisa diambil dari penelitian ini adalah sebagai berikut:

1. Dengan adanya aplikasi e-commerce perusahaan bisa memperluas informasi promosi secara online di PT. Golden Communication.

2. Dapat mengimplementasikan aplikasi e- commerce yang dibuat sebagai alat pemasaran produk di PT. Golden Communication. 


\subsection{Manfaat Penelitian}

Adapun manfaat yang bisa diambil dari penelitian ini adalah sebagai berikut:

1. Dapat meningkatkan dan memperluas promosi penjualan produk komunikasi pada PT. Golden Communication.

2. Perusahaan membagikan kemudahan kepada konsumen untuk berbelanja dan bertransaksi melalui aplikasi e-commerce.

\section{HASIL DAN PEMBAHASAN}

\subsection{Analisa Masalah}

Dalam melakukan penelitian penulis menganalisa sistem yang berjalan pada PT. Golden Communication, penulis menemukan masalah dalam setiap proses malakukan transaksi bisnis dalam menjual produknya ke pembeli proses tersebut belum efektif sehingga menimbulkan beberapa masalah diantaranya:

1. Manajemen pemasaran produk masih dilakukan secara manual yaitu menggunakan sales dan media cetak dalam penyampaian informasi promosi dan penjualan kepada konsumen dan outlet.

2. Belum tersedianya media promosi elektronik untuk memasarkan produk.

\subsection{Diagram Level}

Dibawah ini merupakan diagram level dalam proses sistem e-commerce yang akan dibuat:

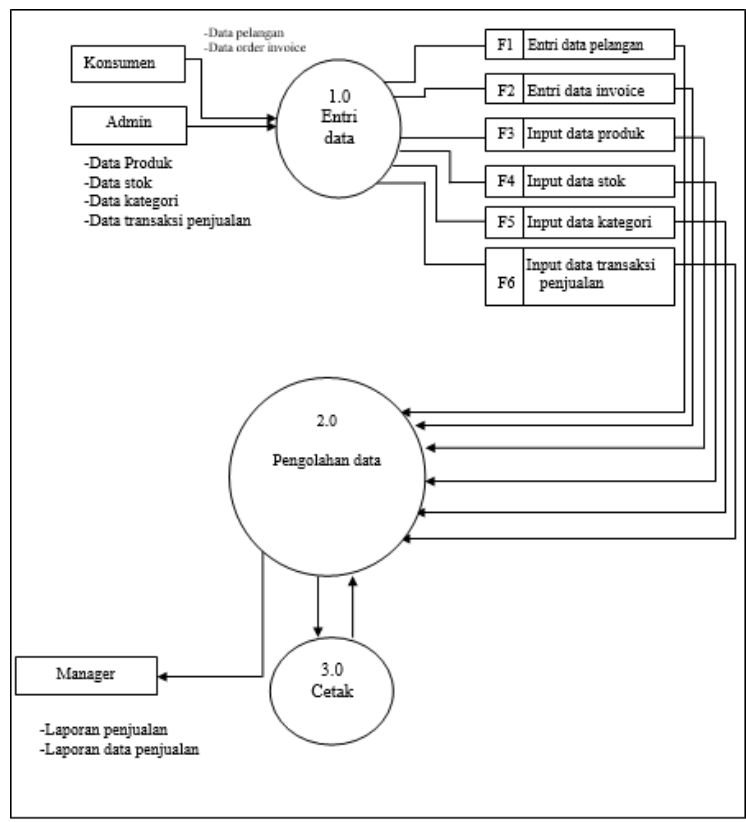

Gambar 3.1. Diagram Level

\subsection{Diagram Rinci}

Dibawah ini merupakan diagram rinci dalam proses sistem e-commerce yang akan dibuat: 

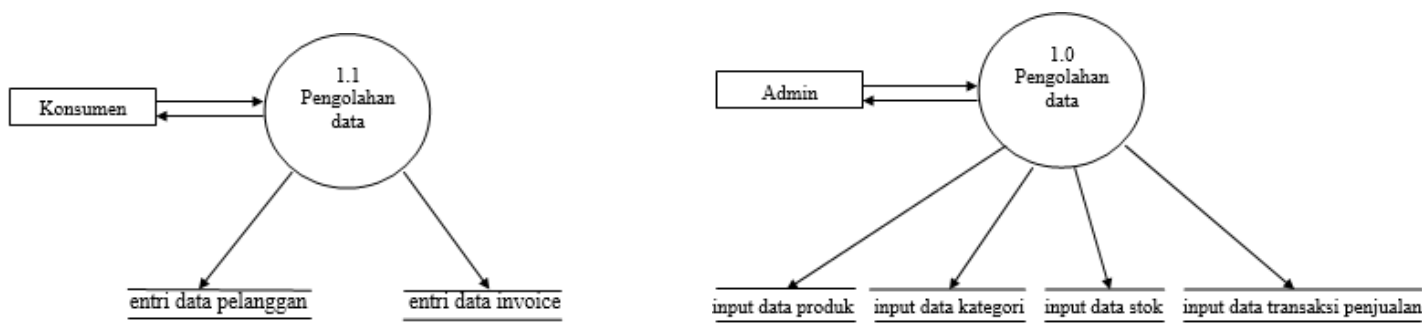

Gambar 3.2. Diagram Rinci Proses

\subsection{Implementasi}

Implementasi sistem menjelaskan tentang alur pembuatan dan kegunaan program yang dibuat beserta tampilan desain Penulis telah mencoba melakukan pengujian setiap halaman, baik merujuk pada suksesuji alamat dan tampilan dari website ini dan hasil dari percobaan tersebut akan di implementasikan di bawah ini. Berikut ini tampilan-tampilan halaman yang ada dalam sistem yang dibuat:

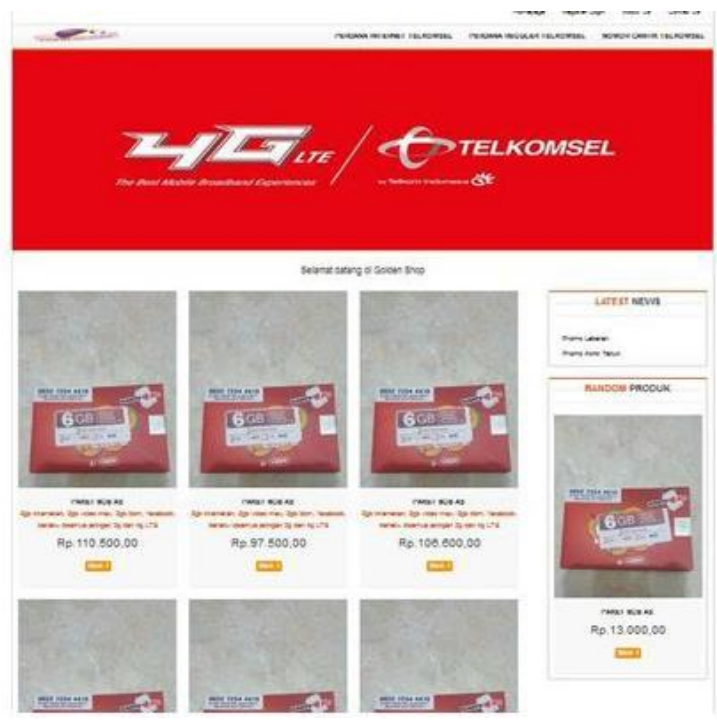

Gambar 3.3. Halaman Utama

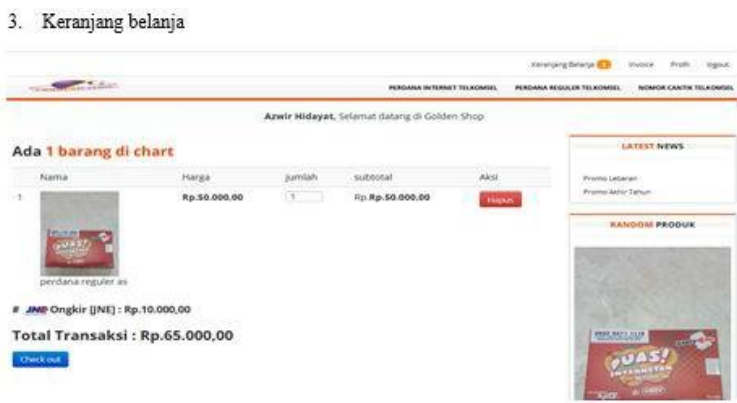

Gambar 3.4. Keranjang Belanja 


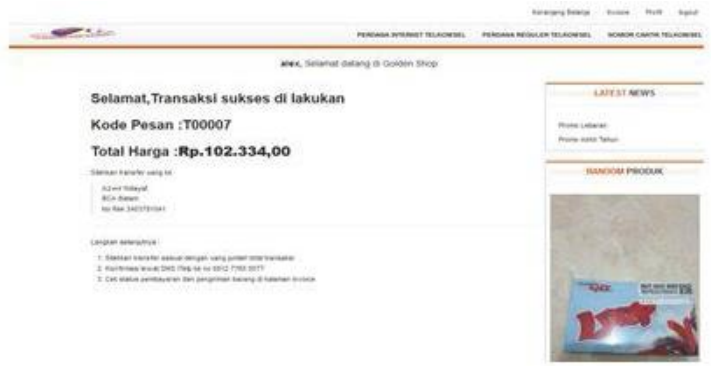

Gambar 3.5. Transaksi

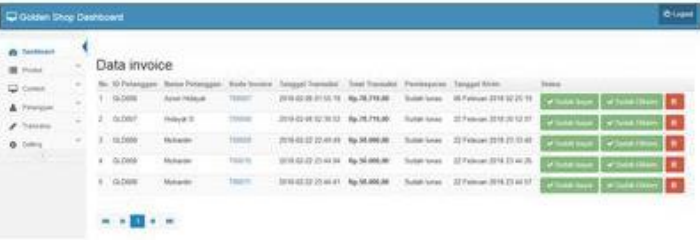

Gambar 3.6. Invoice

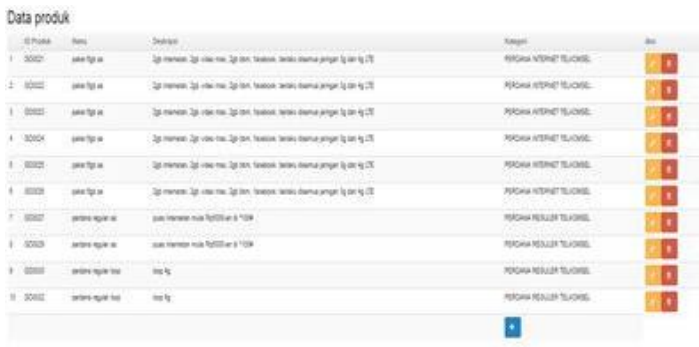

Gambar 3.7. Data Produk

\section{SIMPULAN}

Berdasarkan uraian dan penjelasan dari bab-bab sebelumnya maka penulis dapat mengambil kesimpulan antara lain:

1. Merancang aplikasi e-commerce di PT. Golden Comunication dengan melakukan penelitian, wawancara dan pengamatan

2. Cara mengimplementasikan aplikasi e-commerce pada PT. Golden Communication dengan sistem yang dibuat yaitu e-commerce golden shop

\section{SARAN}

Dalam penulisan skripsi ini ada beberapa saran yang dapat penulis sampaikan antara lain:

1. Sistem e-commerce yang dibuat baru tahap perancangan perlu dikembangkan lagi agar lebih baik jika ingin digunakan.

2. Sistem e-commerce yang dibuat dapat digunakan oleh perusahaan jika sudah ditambahkan sistem security tambahan.

3. Sistem e-commerce yang dibuat masih menggunakan pembayaran transfer, kedepannya sistem dapat ditambahkan dengan pembayaran menggunakan kartu kredit dan paypal. 


\section{DAFTAR PUSTAKA}

Ariana,. dan Robert,S. (2008). Perancangan E-Commerce Sebagai Media Promosi Produk: Jurnal Informatika Vol 5 No 1, Juni 2008.

Bethsani, stevalin. (2009). Analisa Data Dengan Menggunakan ERD dan Model Konseptual Data Warehouse: Jurnal Informatika Vol 5 No 1, Juni 2009.

Fling. (2009). Perancagan Sistem Informasi Sekolah Menggunakan CMS (Studi Kasus Pada SMA Pembagunan Laboratoriom UNP): Jurnal Teknoif Vol. 2 No. 1 April 2009.

Hendrianto, Eko. ( 2014). Pembuatan Sistem Informasi Perpustakaan Berbasis Website Sekolah Menengah Pertama Negeri 1 Donorajo Kabupaten Pacitan: Indonesian Journal on Networking and Security - Volume 3 No 4 - 2014.

Indiasari, D., \& Sidhi, T.A. (2012). Sistem Pencarian Orang Hilang Berbasis Mobile Web Dengan Sosial Network Analisys: Jurnal Universitas Atma Jaya Yogyakarta 2 juli 2011.

Irmawati, Dewi. (2011). Pemanfaatan E-Commerce di Bidang E-Commerce: Jurnal IImiah Orasi Bisnis Edisi ke IV, November 2011.

Iswandy. (2014). Perancangan Sistem Informasi Promosi Spare Part Sepeda Motor Berbasis Web Pada PT.Sigma dan Hearts Cikarang indonesia: Jurnal Nusa Mandiri Vol.2 No.5 2014.

Juahari, Jaidan. (2010). Upaya Usaha Kecil dan Menegah (UKM) Dengan Memanfaatkan ECommerce: Jurnal Sistem Informasi Vol 2 No 1, April 2010.

Maulana, M,S,. (2015). Implementasi E- Commerce Sebagai Media Penjulan Online (Studi Kasus Pada Toko Pastbrik Kota Malang: Jurnal Administrasi Bisnis Vol 29 No 1, Desember 2015.

Muhbib, Alfian. (2013). Implementasi Desktop Sistem Investasi Pada Hudi Motor Karangrayung Grobogan: Jurnal Dian Nurwanstoro Vol 29 No 1, Desember 2013.

Munawar,. (2009). Perancangan E-Commerce Sebagai Media Promosi

Permatasari, R.D., Setyabuhi, A.L. and Anggra, F., 2019. ARSITEKTUR SISTEM INFORMASI OBJEK WISATA KOTA BATAM. JR: JURNAL RESPONSIVE Teknik Informatika, 2(2).

Setyabudhi, A. L. (2017). Perancangan Sistem Informasi Pengolahan Data Absensi dan Pengambilan Surat Cuti Kerja Berbasis Web. JR: JURNAL RESPONSIVE Teknik Informatika, $1(1)$. 